\title{
Histopathological diagnosis of intra- and extrahepatic neonatal cholestasis
}

J.L. Santos ${ }^{1}$,

H. Almeida ${ }^{2}$,

C.T.S. Cerski ${ }^{3}$ and

T.R. Silveira ${ }^{1}$
Departamentos de ${ }^{1}$ Pediatria, ${ }^{2}$ Cirurgia and ${ }^{3}$ Patologia, Universidade Federal do Rio Grande do Sul, Porto Alegre, RS, Brasil

\section{Correspondence \\ J.L. Santos \\ Rua Fernandes Vieira, 501, apto. 02 \\ 90035-091 Porto Alegre, RS \\ Brasil \\ Fax: 55 (051) 312-2090 \\ E-mail:kapa@poa.nutecnet.com.br. \\ Part of a Master's thesis presented by J.L. Santos to the Departamento de Gastroenterologia, UFRGS, Porto Alegre, RS.}

Received June 4, 1997 Accepted March 26, 1998

\section{Abstract}

The histopathology of the liver is fundamental for the differential diagnosis between intra- and extrahepatic causes of neonatal cholestasis. However, histopathological findings may overlap and there is disagreement among authors concerning those which could discriminate between intra- and extrahepatic cholestasis. Forty-six liver biopsies (35 wedge biopsies and 11 percutaneous biopsies) and one specimen from a postmortem examination, all from patients hospitalized for neonatal cholestasis in the Pediatrics Service of Hospital de Clínicas de Porto Alegre, were prospectively studied using a specially designed histopathological protocol. At least 4 of 5 different stains were used, and 46 hepatic histopathological variables related to the differential diagnosis of neonatal cholestasis were studied. The findings were scored for severity on a scale from 0 to 4 . Sections which showed less than 3 portal spaces were excluded from the study. Sections were examined by a pathologist who was unaware of the final diagnosis of each case. Bile tract permeability was defined by scintigraphy of the bile ducts and operative cholangiography. The F test and discriminant analysis were used as statistical methods for the study of the hepatic histopathological variables. The chi-square method with Yates correction was used to relate the age of the patients on the date of the histopathological study to the discriminatory variables between intraand extrahepatic cholestasis selected by the discriminant function test. The most valuable hepatic histopathological variables for the discrimination between intra- and extrahepatic cholestasis, in decreasing order of importance, were periportal ductal proliferation, portal ductal proliferation, portal expansion, cholestasis in neoductules, foci of myeloid metaplasia, and portal-portal bridges. The only variable which pointed to the diagnosis of intrahepatic cholestasis was myeloid metaplasia. Due to the small number of patients who were younger than 60 days on the date of the histopathological study $(\mathrm{N}=6)$, no variable discriminated between intra- and extrahepatic cholestasis before the age of 2 months and all of them, except for the portal expansion, were discriminatory after this age. In infants with cholestasis, foci of myeloid metaplasia, whenever present in the liver biopsy, suggested intrahepatic cholestasis. Periportal ductal proliferation, portal ductal proliferation, portal expansion, cholestasis in neoductules, portal cholestasis and portal-portal bridges suggested extrahepatic obstructive cholestasis.
Key words

- Liver biopsy

- Neonatal cholestasis

- Biliary atresia 


\section{Introduction}

Neonatal cholestatic jaundice is defined by the persistence of jaundice of variable intensity, choluria and hypocholic or acholic stools for more than 10 days, occurring during the first months of life (1). Its reported frequency is variable. In Australia, the prevalence was of 1:5000 liveborn infants (2) and in Norway, Henriksen et al. (3) reported 1 case of neonatal cholestasis per 9000 liveborn infants. In the Pediatric Gastroenterology sector of Hospital de Clínicas de Porto Alegre, about $25 \%$ of the outpatient visits are related to neonatal cholestasis (4). Neonatal cholestasis is caused by two large groups of diseases, i.e., extrahepatic (EHC) and intrahepatic (IHC) conditions. This division based on the presence or absence of extrahepatic obstruction to bile flow is useful with respect to the intervention strategy to be used, since in terms of management, the patient belonging to the first group needs to undergo surgery, whereas those belonging to the second group are subjected to nonsurgical treatment. Although there is a large number of possible causes, the relative frequency of idiopathic neonatal hepatitis (INH) and of biliary atresia (BA) far exceeds that of any other etiology. In the United States, these two disorders account for 70 to $80 \%$ of all cases of neonatal cholestasis (5). In Brazil, Silveira (4), in a study of 287 neonatal cholestasis cases, found a higher frequency of intrahepatic than extrahepatic causes of neonatal cholestasis. Taken together, INH and BA accounted for about $54 \%$ of all cases. INH is an inflammation of the neonatal liver of unknown etiology which was histopathologically defined by Craig and Landing in 1952 (6). Balistreri (7) estimated its frequency at 1.25 cases per 10,000 livebirths. BA is a disease occurring only in childhood whose cause is still unknown and which consists of total obliteration of part or all of the extrahepatic bile ducts. Its frequency is $1: 8,000$ to $1: 15,000$ livebirths and, according to Balistreri (8), one-third of neonatal cholestasis cases are due to BA. After 1968, with the spread of the Kasai technique (portoenterostomy) in the Western world, many cases which were classified as "noncorrectable BA" became surgically correctable with good results (9-13). Other authors agree that it is of fundamental importance to perform the surgery before eight weeks of life in order for it to be effective and that the results of surgeries performed after this period are poor. Thus, the differential diagnosis between obstructive extrahepatic causes, particularly BA, and intrahepatic causes, especially INH, is of great importance. Among the tests used for this purpose, the liver biopsy is of great importance.

The differential histopathological study of neonatal cholestasis is performed by determining the presence or absence of variables which characterize either group of diseases - IHC or EHC. The histopathological characterization of INH by Craig and Landing (6) introduced the perspective of morphological differentiation between INH and BA. At large centers, the histopathological study is the method of choice, among others such as scintigraphy of the bile ducts, duodenal intubation, ultrasonic echography and cholangiography. Correction rates of about $90 \%$ after this differential diagnosis through a liver biopsy have been reported in the literature (14-17). Previous experience of the pathologist with this group of diseases is essential, since there are more similarities than differences between IHC and EHC from an anatomopathological point of view. The difficulties for a correct differential diagnosis, according to Dahms (18), include: a) a specimen with few portal triads, b) the overestimation of the mild bile duct hyperplasia in INH, c) the nonrecognition that infants younger than 4 weeks with BA may not yet show portal duct proliferation, and d) the nonrecognition that this proliferation is not exclusive of BA.

In 1985, Zerbini (19) assessed 49 hepatic 
histopathological variables in 100 biopsies from 78 infants with neonatal cholestasis in terms of their discriminant value in the differential diagnosis between IHC and EHC. She divided the variables into two classes, "indicating variables" and "guiding variables" of the diagnosis of EHC. The former, with a higher discrimination power $(\mathrm{P} \leq 0.0001)$, includes portal ductal proliferation, distribution of the portal proliferation in the portal spaces, overall degree of cholestasis, cholestasis in the portal neoductules, cholestasis in the bile capillaries, and portal fibrosis. The second class, with lower discriminatory power (P between 0.0001 and 0.05 ), includes myeloid metaplasia, portal-portal bridges, periductal fibrosis, neutrophils in the general inflammatory infiltrate, swelling of hepatocytes and giant cells.

The aim of the present study was to define the discriminant value of the hepatic histopathological variables in the differential diagnosis of neonatal cholestasis in patients with this disorder seen at the sector of Pediatric Gastroenterology of the Pediatrics Service of Hospital de Clínicas de Porto Alegre, and to identify the hepatic histopathological variables which discriminated between IHC and EHC before and after the age of two months.

\section{Material and Methods}

The slides of 46 biopsies ( 35 wedge biopsies and 11 percutaneous biopsies) and one from a postmortem examination, all from patients hospitalized for neonatal cholestasis at the Pediatrics Service of Hospital de Clínicas de Porto Alegre, were prospectively studied from December 1987 to January 1991. At least 4 of 5 different stains were used, and 46 histopathological variables from the protocol introduced by Zerbini (19) were assessed, and the findings were scored on a 0 to 4 scale according to the degree of severity (0 - absent; 1 - mild; 2 - moderate-mild; 3 - moderate-severe; 4 - severe). The stains used were hematoxylin-eosin, trichromic green, picrosirius, PAS and reticulin. Sections of percutaneous biopsies which had less than 3 portal spaces were excluded from the study. Slides were scored by a pathologist who was unaware of the final diagnosis of each case. The cases were divided into 2 groups according to the diagnostic histopathologic impression: extrahepatic biliary pattern (EHBP) or parenchymatous pattern (PP). Biliary permeability was defined in each case by scintigraphy of the bile ducts and, in the absence of excretion of the radiotracer to the duodenum by this method, by operative cholangiography.

\section{Data analysis}

Discriminant analysis was used as a statistical method for the study of the histopathological variables in order to determine possible significant differences between the EHC and IHC groups based on information of independent variables, and which independent variables would contribute to the differentiation between the 2 groups. In order to use this technique, the variables were originally treated as being continuous. Due to the high number of variables being studied, a previous selection of these variables by means of the F test was carried out, and only those which were found to be significant by this test were subjected to the discriminant analysis, with the level of significance set at 5\%. After selection by the $F$ test, 22 variables of 47 patients were assessed by the discriminant analysis test. In this test the total sample $(\mathrm{N}=47)$ was divided into two groups: the first group $(\mathrm{N}=30)$ was used to obtain the discriminant function, and the second $(\mathrm{N}=$ 17) for the discriminant function test (accuracy). A "stepwise" computational model was used to assess the independent variables in each step, including or excluding them from the model according to their discriminatory power. Thus, it was possible to estab- 
lish which variables were most significant for the distinction between the EHC and IHC groups.

The chi-square method with Yates correction was used to relate the age of the patients at the time of liver biopsy to the

Table 1 - The most significant hepatic histopathological variables for the distinction between IHC and EHC according to the discriminant function test in this study.

\begin{tabular}{lc}
\hline $\begin{array}{l}\text { Histopathological } \\
\text { variable }\end{array}$ & $\begin{array}{c}\text { Canonical discriminant } \\
\text { function coefficient }\end{array}$ \\
\hline 1. Periportal ductal proliferation & -0.44342 \\
2. Portal ductal proliferation & -0.32899 \\
3. Portal expansion & -0.30354 \\
4. Cholestasis in neoductules & -0.26593 \\
5. Portal cholestasis & -0.25241 \\
6. Foci of myeloid metaplasia & +0.24917 \\
7. Portal-portal bridges & -0.22414 \\
8. Focal necrosis & -0.19082 \\
9. Cholestasis in canaliculi & -0.17636 \\
10. Periductal fibrosis & -0.14359 \\
11. Central portal bridges & -0.10213 \\
\end{tabular}

Table 2 - Discriminant hepatic histopathological variables between $\mathrm{IHC}$ and $\mathrm{EHC}$ in relation to $\mathrm{pa}-$ tient age.

No variable discriminated between $\mathrm{IHC}$ and $\mathrm{EHC}$ in patients younger than 60 days. Chi-square with Yates correction.

\begin{tabular}{lcc}
\hline Variable & \multicolumn{2}{c}{$\begin{array}{c}\text { Patients older than } \\
60 \text { days }(\mathrm{N}=41)\end{array}$} \\
\cline { 2 - 3 } & $\chi^{2}$ & $\begin{array}{c}\text { Significance } \\
\text { level }\end{array}$ \\
\hline $\begin{array}{l}\text { Periportal ductal } \\
\text { proliferation }\end{array}$ & 11.99648 & 0.00053 \\
$\begin{array}{l}\text { Portal ductal } \\
\text { proliferation }\end{array}$ & 16.08518 & 0.00006 \\
$\begin{array}{l}\text { Myeloid } \\
\text { metaplasia foci }\end{array}$ & 8.82869 & 0.00297 \\
$\begin{array}{l}\text { Portal } \\
\text { cholestasis } \\
\text { Cholestasis in } \\
\text { neoductules }\end{array}$ & 13.96010 & 0.00019 \\
$\begin{array}{l}\text { Portal-portal } \\
\text { bridges }\end{array}$ & 11.30285 & 0.00077 \\
\hline
\end{tabular}

discriminant hepatic histopathological variables between IHC and EHC selected by the discriminant function test.

The significance level adopted for the statistical tests was 0.05 (two tailed).

\section{Results}

The following variables were considered to be the most significant according to the discriminant analysis test in the discrimination between IHC and EHC, in decreasing order of the coefficient value of the canonical discriminant function: periportal ductal proliferation, portal ductal proliferation, portal expansion, cholestasis in neoductules, portal cholestasis, foci of myeloid metaplasia, portal-portal bridges, focal necrosis, cholestasis in canaliculi, periductal fibrosis and portal-central bridges (Table 1). Figure 1a represents the variables which indicate intrahepatic cholestasis. Since coefficients around 0.3000 (20) are considered significant in the discriminant analysis test, the variables from 8 to 11 in Table 1 contribute little to the histopathological differential diagnosis of neonatal cholestasis. The canonical correlation of the test was 0.9237 and the test significance was $88.24 \%$. We can see that the sixth variable, foci of myeloid metaplasia, shows a canonical discriminant function coefficient with a plus, thus being the only variable related to the diagnosis of a nonobstructive intrahepatic cause; the remaining variables, with a minus, point to an EHC diagnosis. Figure $1 \mathrm{~b}$ represents the myeloid metaplasia variable.

Table 2 presents the age of the patients at the time of the liver biopsy related to the significance of the variables selected in the discriminant analysis test for the patients studied. Only six patients were younger than 60 days on the date the histopathological material was collected. No hepatic histopathological variables discriminated between IHC and EHC before 2 months of age. After 60 days of life, all variables selected by the 
discriminant function test, except for portal expansion, were important for the differential diagnosis between intra- and extrahepatic cholestasis. The variables with the highest significance level were portal ductal proliferation and cholestasis in neoductules.

\section{Discussion}

Most authors find more support for a differential diagnosis among variables which point to EHC (Table 3). Very few histopathological variables indicate IHC and, according to some $(14,19,21)$, no variable suggests this group of diseases. However, in our study there was a relationship between the presence of myeloid metaplasia and the existence of IHC. According to Desmet (22), myeloid metaplasia is a nonspecific finding. However, this author found that in cases of early severe BA, i.e., 1/4 of the cases of BA, myeloid metaplasia or gigantocyte proliferation is not found. In the study by Zerbini
(19), a severe degree of myeloid metaplasia was only found in the extrahepatic cholestasis group between 2 and 4 months of age. Before this time, myeloid metaplasia was milder and occurred in both intra- and extrahepatic cholestasis. The author found no histological parameter for the diagnosis of intrahepatic cholestasis. Our finding is consistent with the observations by Allagille (1), which include extramedullary hematopoiesis among those variables which characterize IHC. Recently, Romero (23), analyzing the histopathological variables which are useful in the discrimination among different causes of neonatal cholestasis, included foci of extramedullary hematopoiesis among those which characterize idiopathic neonatal hepatitis. In our study and in Zerbini's study (19), giant cell transformation was a nonspecific finding. Giant cell transformation originates from a syncytial fusion of several hepatocytes (22) and its biological meaning is unknown. In contrast to data reported by Craig
$1 a$

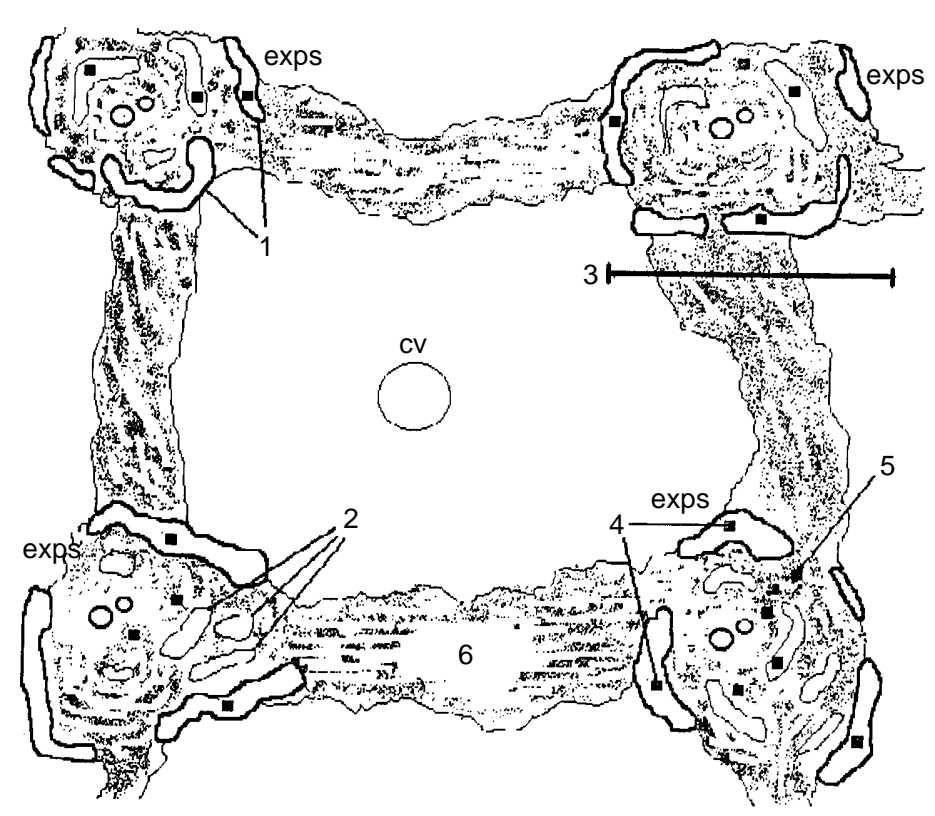

$1 b$
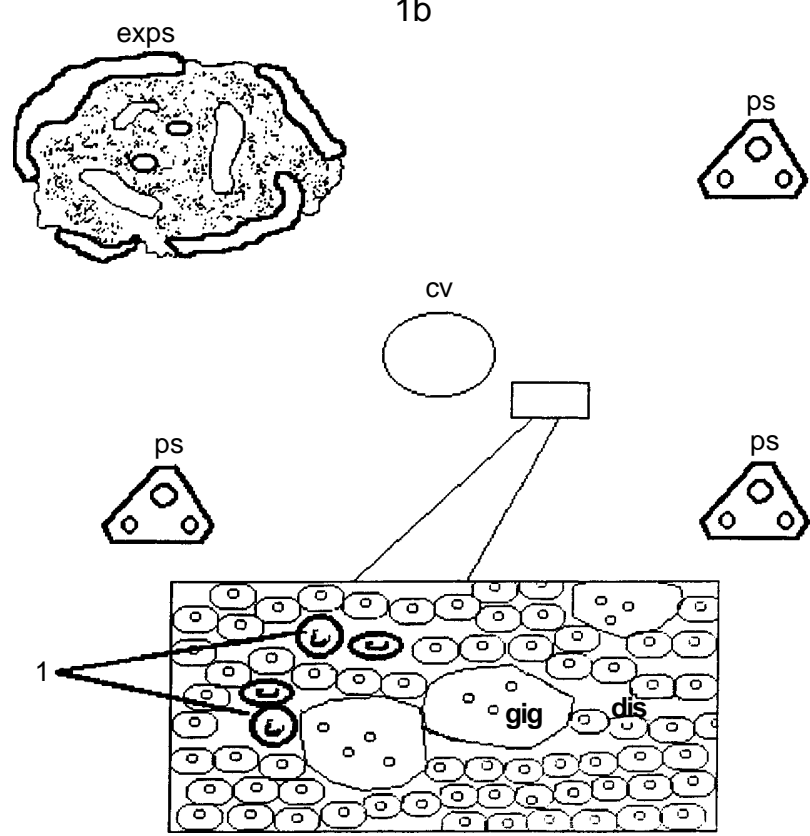

Figure 1 - Hepatic histopathological variables which indicate the intra- and extrahepatic forms of cholestasis in this study. 1a, Extrahepatic cholestasis: 1 - periportal ductal proliferation; 2 - portal ductal proliferation; 3 - portal expansion; 4 - cholestasis in neoductules; 5 - portal cholestasis; 6 - portal-portal bridges. 1b, Intrahepatic cholestasis: 1 - myeloid metaplasia. dis, Lobular disarray; ps, portal space; exps, expanded portal space; gig, gigantocytes; cv, central vein. 


\begin{tabular}{|c|c|c|}
\hline References & Data indicating EHC & Data indicating IHC \\
\hline Kasai et al. (25) & $\begin{array}{l}\text { Portal fibrosis, portal ductal proliferation, } \\
\text { neoductule cholestasis, Kupffer cell } \\
\text { cholestasis, severe portal expansion, } \\
\text { marked lobular fibrosis with disarray } \\
\text { of the lobular architecture even } \\
\text { before the age of } 6 \text { months }\end{array}$ & $\begin{array}{l}\text { More marked hepatocytic degenerative } \\
\text { alterations and giant cell transformation }\end{array}$ \\
\hline Bennett (26) & $\begin{array}{l}\text { Portal ductal proliferation (particularly } \\
\text { before the first } 3 \text { or } 4 \text { weeks of life), } \\
\text { portal fibrosis. "Biliary infarcts" } \\
\text { (pathognomonic of extra-hepatic biliary } \\
\text { atresia) }\end{array}$ & Intralobular fibrosis, early lobular disarray \\
\hline $\begin{array}{l}\text { Brough and } \\
\text { Bernstein (14) }\end{array}$ & $\begin{array}{l}\text { Diffuse portal ductal proliferation - } \\
\text { the most important criterion. } \\
\text { Others: proliferation of ducts on } \\
\text { the periphery of the portal spaces }\end{array}$ & - \\
\hline Zerbini (19) & $\begin{array}{l}\text { Portal ductal proliferation, cholestasis } \\
\text { in neoductules, marked canalicular } \\
\text { cholestasis, marked portal fibrosis }\end{array}$ & - \\
\hline Shiraki et al. (21) & $\begin{array}{l}\text { Cholestasis in neoductules } \\
\text { (the most specific variable) }\end{array}$ & - \\
\hline Alagille (1) & $\begin{array}{l}\text { Neoductule proliferation, portal and } \\
\text { perilobular fibrosis, portal "biliary } \\
\text { plugs", normal lobular architecture, } \\
\text { little inflammatory response }\end{array}$ & $\begin{array}{l}\text { Lobular disarray, giant cell proliferation, } \\
\text { hepatocellular necrosis, minimal fibrosis, } \\
\text { rare formation of neo-ductules, steatosis, } \\
\text { extra-medullary hematopoiesis }\end{array}$ \\
\hline Present study & $\begin{array}{l}\text { Periportal ductal proliferation, } \\
\text { portal ductal proliferation, portal } \\
\text { expansion, cholestasis in neoductules, } \\
\text { portal cholestasis, portal-portal bridges }\end{array}$ & Foci of myeloid metaplasia \\
\hline
\end{tabular}

and Landing (6), it is a histopathological variable which is more specific for age than for causal disease, thus not serving as an IHC marker.

According to several authors, the changes which indicate EHC more often are portal ductal proliferation, cholestasis in neoductules and portal fibrosis (Table 3). In our study, we found that portal ductal proliferation and cholestasis in neoductules were discriminatory variables between IHC and EHC. Concerning portal fibrosis, we should clarify that it is one of the elements which characterize portal expansion, in addition to edema and ductal portal proliferation $(18,19)$. Chandra (24) found portal expansion in all cases of BA, with distribution in all portal triads and with a varying extent of fibrosis. Kasai et al. (25) presented it as a feature of BA. Bennett (26) differentiates the fibrosis pattern of both groups of disease as being predominantly portal in EHC and lobular in IHC. However, in the present study the most important indicator of EHC was periportal ductal proliferation, whose importance had already been demonstrated by Brough and Bernstein in 1974 (14). Portal ductal proliferation originates from the mitotic prolifera- 
tion of the preexisting ducts (particularly in complete mechanical biliary obstruction) and from ductular metaplasia of hepatocytes of zone 1 of the Rappaport acinus (mainly in cases of incomplete obstruction of the biliary flow) (22). The study by Cocjin et al. (27) seems to confirm the idea that in BA there is a coexistence of an important ductular metaplasia with mitotic proliferation of the biliary ductules on a smaller scale. According to Tan et al. (28), the portal ductal proliferation, at least on the hilar hepatic area, would be a reactive phenomenon to the progressive obstruction of the biliary flow due to fibrosis.

Cholestasis in neoductules is considered by Brough and Bernstein (14) to be a nonspecific finding, and by Shiraki et al. (21) as the most specific discriminatory element between EHC and IHC. Desmet (22) calls this variable "ductular bilirubinostasis", placing it among those findings characteristic of BA in the histopathological test. The fifth variable selected in the present study, portal cholestasis, is directly correlated to cholestasis in neoductules.

The seventh selected variable, portal-portal bridges, originates from what Desmet (22) calls "fibrosing piecemeal necrosis", i.e., the periportal fibrosis process which leads to the formation of fibrous septa amid portal spaces, which are still potentially reversible lesions, since the intrahepatic vascular relationships are preserved. In our study, as in Zerbini's (19), this finding favored the EHC diagnosis. In Zerbini's work there was no IHC case in patients younger than 2 months. According to Cocjin's study (27), the fibrogenesis process seems to be due to the proliferation of Ito cells for the formation of the periductular stroma surrounding the neoductules at the periphery of the portal spaces.

By comparing the present findings with Zerbini's indicating and guiding variables (19), we can see an agreement relative to the portal ductal proliferation and portal chole- stasis in neoductules in the group of the indicating variables. Portal fibrosis, assigned by Zerbini to this group, was included in the portal expansion variable found by us. Among the guiding variables, our findings agree in terms of portal-portal bridges and myeloid metaplasia. In the present study, the two latter variables had the lowest canonical discriminant function coefficients among the variables selected (Table 1), which seems to agree with Zerbini's study, in which they were placed in the group with less discriminatory capacity between IHC and EHC.

Romero (23) includes among the histopathological variables which characterize BA the proliferation of bile ducts, portal expansion, fibrosis in portal tracts, the presence of biliary cylinders, the disarray of hepatic parenchyma and the absence of a marked proliferation of giant cells. Among the characteristics of INH, the author points to the loss of parenchyma organization, the existence of important giant cell proliferation, the bilirubinic pigmentation of the hepatocytes, the presence of biliary cylinders to a lesser extent and foci of myeloid metaplasia. As previously discussed, this theoretical description does not reflect the complexity of the differential diagnosis of neonatal cholestasis by histopathology, since there is a broad overlap of the findings for the intra- and extrahepatic cholestasis groups. Elements such as disarray of the hepatic parenchyma, proliferation of giant cells and the presence of biliary cylinders have been found to be nonspecific.

A criterion the pathologist has to take into account in this diagnostic differentiation is the age of onset of these histopathological changes in both IHC and EHC. The proliferation of ducts in portal spaces is a later finding in INH than in BA (19). However, even in children with BA portal ductal proliferation may be absent in patients younger than 4 weeks (18). The histopathological variables which indicate EHC, but which may be present in cases of IHC, usu- 
ally appear later and in a more focal way in this second group of diseases. In our study, only 6 patients underwent biopsy before the age of two months, a fact that did not permit the use of this criterion as an adjuvant in the differential diagnosis between IHC and EHC. These data stress the need for early investigation of patients with neonatal cholestasis through a liver biopsy to provide a more adequate diagnosis (29). The histopathological changes in neonatal cholestasis reflect a dynamic process, with different characteristics in distinct age groups, a fact which should be taken into account by the pathologist who is investigating it.

To conclude, in this study seven histopathological variables indicated EHC, namely, periportal ductal proliferation, portal ductal proliferation, portal expansion, cholestasis in neoductules, portal cholestasis and portal-portal bridges. Only myeloid metaplasia pointed to a diagnosis of IHC.

\section{References}

1. Alagille D (1995). Prolonged obstructive jaundice including calculous and noncalculous gallbladder conditions. In: Roy CC, Silverman A \& Allagille D (Editors), Pediatric Clinical Gastroenterology. 4th edn. Mosby-Year Book, Inc., St. Louis.

2. Danks DM, Campbell PE \& Smith $A$ (1977). Prognosis of babies with neonatal hepatitis. Archives of Disease in Childhood, 52: 360-367.

3. Henriksen NT, Drablos P \& Aagenaes $O$ (1981). Cholestatic jaundice in infancy. The importance of familial and genetic factors in aetiology and prognosis. Archives of Disease in Childhood, 56: 622627.

4. Silveira TR (1997). Icterícia colestática neonatal. In: Miura E \& Procianoy RS (Editors), Neonatologia - Princípios e Prática. 2nd edn. Editora Artes Médicas, Porto Alegre.

5. Balistreri WF (1985). Neonatal cholestasis. Journal of Pediatrics, 106: 171-184.

6. Craig JM \& Landing BH (1952). Form of hepatitis in neonatal period simulating biliary atresia. American Medical Association Archives of Pathology, 54: 321-333.

7. Balistreri WF (1991). Neonatal cholestasis. In: Hoofnagle JF \& Goodman Z (Editors), Liver Biopsy - Interpretation for the 1990's. Clinicopathologic Correlations in Liver Diseases. American Association for the Study of Liver Disease. Library of Congress catalog card number ISBN: 1-55642209-1. Postgraduate Course.

8. Balistreri WF (1987). Liver disease in infancy and childhood. In: Schiff $L$ \& Schiff E (Editors), Disease of the Liver. 6th edn. J.B. Lippincott Company, Philadelphia.

9. McClement JW, Howard ER \& Mowat AP (1985). Results of surgical treatment for extrahepatic biliary atresia in United King- dom, 1980-2. British Medical Journal, 200: 345-347.

10. Bujanover $Y$ (1987). Prognosis of neonatal cholestatic jaundice. Journal of Pediatric Gastroenterology and Nutrition, 6: 163166.

11. Grosfeld JL, Fitzgerald JF, Predaina R, West KW, Vane DW \& Rescorla FJ (1989). The efficacy of hepatoportoenterostomy in biliary atresia. Surgery, 106: 692-701.

12. Ohi R, Chiba T, Endo N, Goto M \& Ibrahim M (1990). Long-term follow-up after surgery for patients with biliary atresia. Journal of Pediatric Surgery, 25: 442-445.

13. Questa $\mathrm{H}$, Valone $\mathrm{P}$, Wacholder V, Rojas L, Williams E, Pedreira A \& Ciocca M (1993). Atresia de vias biliares: Seguimos operando tarde? Revista de Cirugía Infantil, 3 (Suppl 4): 118-151.

14. Brough AJ \& Bernstein J (1974). Conjugated hyperbilirubinemia in early infancy. A reassessment of liver biopsy. Human Pathology, 5: 507-516.

15. Ferry GD, Selby ML, Udall J, Finegold M \& Nichols B (1985). Guide to early diagnosis of biliary obstruction in infancy. Review of 143 cases. Clinical Pediatrics, 24: 305-311.

16. Tolia V, Dubois RS, Kagalwalla A, Fleming $S$ \& Dua V (1986). Comparison of radionuclear scintigraphy and liver biopsy in the evaluation of neonatal cholestasis. Journal of Pediatric Gastroenterology and Nutrition, 5: 30-34.

17. Cox K, Stadalnik RC, McGahan JP, Sanders K, Cannon RA \& Ruebner BH (1987). Hepatobiliary scintigraphy with technetium-99m disofenin in the evaluation of neonatal cholestasis. Journal of Pediatric Gastroenterology and Nutrition, 6: 885891.

18. Dahms BB (1991). The pathology of bil- iary atresia and neonatal hepatitis. In: Hoofnagle JF \& Goodman Z (Editors), Liver Biopsy - Interpretation for the 1990's. Clinicopathologic Correlations in Liver Diseases. American Association for the Study of Liver Diseases. Library of Congress catalog card number ISBN: 155642-209-1. Postgraduate Course.

19. Zerbini MCN (1985). Análise semiquantitativa e quantitativa de variáveis histopatológicas no diagnóstico diferencial das formas intra e extra-hepática da síndrome colestática do recém-nascido. Doctoral thesis, Universidade Federal de São Paulo, São Paulo.

20. Hair JF, Anderson RE \& Tatham RL (1987). Multivariate Data Analysis with Readings. 2nd edn. Macmillan Publishing Company, New York.

21. Shiraki K, Okada T \& Tanimoto K (1987). Evaluation of various diagnostic methods in biliary atresia. In: Ohi R (Editor), Biliary atresia. Proceedings of the 4th International Symposium on Biliary Atresia. Professional Postgraduate Services, Tokyo.

22. Desmet VJ (1992). Pathology of pediatric cholestasis. In: Falk Symposium 63. Paediatric Cholestasis. Novel Approaches to Treatment. Kluwer Academic Press, London.

23. Romero R (1996). Disorders of the liver primary and secondary. In: Walker-Smith JA, Hamilton JR \& Walker WA (Editors), Practical Pediatric Gastroenterology. 2nd edn. B.C. Decker Inc., Hamilton, Ontario.

24. Chandra RS (1987). Histopathology of the liver and the fibrous remnants in biliary atresia. In: Ohi R (Editor), Biliary Atresia. Proceedings of the 4th International Symposium on Biliary Atresia. Professional Postgraduate Services, Tokyo.

25. Kasai M, Yakovac WC \& Koop CE (1962). 
Liver in congenital biliary atresia and neonatal hepatitis - a histopathologic study. Archives of Pathology, 74: 152-162.

26. Bennett DE (1964). Problems in neonatal obstructive jaundice. Pediatrics, 33: 735748.

27. Cocjin J, Rosenthal P, Buslon V, Luk L, Barajas L, Geller SA, Ruebner B \& French
S (1996). Bile ductule formation in fetal, neonatal, and infant livers compared with extrahepatic biliary atresia. Hepatology, 24: 568-574.

28. Tan CEL, Driver M, Howard ER \& Moscoso GJ (1994). Extrahepatic biliary atresia: a first-trimester event? Clues from light microscopy and immunohistochem- istry. Journal of Pediatric Surgery, 29: 808-814.

29. Santos JL, Silveira TR, Almeida H, Carvalho PA \& Cerski CTS (1997). Colestase neonatal - atraso no encaminhamento de crianças para diagnóstico diferencial. Jornal de Pediatria, 73: 32-36. 